\title{
The Pathophysiology, Diagnosis and Current Management of Acute Compartment Syndrome
}

\author{
James Donaldson ${ }^{*}, 1$, Behrooz Haddad ${ }^{2}$ and Wasim S. Khan ${ }^{2}$ \\ ${ }^{1}$ Holland Orthopaedic and Arthritic Centre, Toronto, Canada \\ ${ }^{2}$ UCL Institute of Orthopaedics and Musculoskeletal Sciences, Royal National Orthopaedic Hospital, Stanmore, UK
}

\begin{abstract}
Acute compartment syndrome (ACS) is a surgical emergency warranting prompt evaluation and treatment. It can occur with any elevation in interstitial pressure in a closed osseo-fascial compartment. Resultant ischaemic damage may be irreversible within six hours and can result in long-term morbidity and even death. The diagnosis is largely clinical with the classical description of 'pain out of proportion to the injury'. Compartment pressure monitors can be a helpful adjunct where the diagnosis is in doubt. Initial treatment is with the removal of any constricting dressings or casts, avoiding hypotension and optimizing tissue perfusion by keeping the limb at heart level. If symptoms persist, definitive treatment is necessary with timely surgical decompression of all the involved compartments. This article reviews the pathophysiology, diagnosis and current management of ACS.
\end{abstract}

Keywords: Compartment pressure monitoring, compartment syndrome, fasciotomy, ischaemic contracture, myofascial compartment.

\section{INTRODUCTION}

Richard von Volkmann first described compartment syndrome in 1881 [1]. He suggested that paralysis and contracture came simultaneously as a result of an interruption to the blood supply of the affected muscles. The first surgeon to reproduce ischaemic contracture in animals was Paul Jepson in 1924 [2] whilst working at the Mayo Foundation. He also demonstrated that prompt surgical decompression could prevent these contractures. Acute compartment syndrome (ACS) is now considered a surgical emergency warranting prompt evaluation and treatment.

\section{PATHOPHYSIOLOGY}

ACS is defined as 'a critical pressure increase within a confined compartmental space causing a decline in the perfusion pressure to the tissue within that compartment' [36]. It can occur with any elevation in interstitial pressure within an osseo-fascial compartment. Tissue perfusion is proportional to the difference between capillary perfusion pressure (CPP) and the interstitial fluid pressure.

When fluid enters a fixed volume compartment, for example from bleeding, both the tissue and venous pressure increase. When this exceesds the CPP, capillary collapse with ensuing muscle and nerve ischaemia occur. A similar reduction occurs in the CPP when the compartment size decreases (e.g. external compression) due to an increase in intracompartmental pressure, as well as a reduction in the arteriolar pressure. Fig. (1) below displays the cycle of events and the development of acute compartment syndrome.

*Address correspondence to this author at the 62 Hunter Street, Toronto, M4J 1C2, Canada; Tel: +1 416-967-8500; Fax: +1 416-967-8501;

E-mail: jamesrdonaldson@gmail.com
Compartment syndromes can arise in any area of the body that has little or no capacity for tissue expansion.

The commonest cause of all ACSs are tibial shaft fractures with a range from $2-9 \%[7,8]$. After the leg, the next commonest location is in the forearm, but almost any compartment can be affected: arm [9], thigh [10], foot [11], buttock [12], hand [13], and abdomen [14]. Poor patient positioning in unconscious patients for long periods of time can also contribute to the aetiology of ACS [15].

Any internal or external event that increases intracompartmental pressure can cause a compartment syndrome. Table 1 below shows some of the more common causes.

Table 1. Common causes of ACS.

\begin{tabular}{|l|l|}
\hline Fracture & Burns \\
\hline Crush injury & Infection \\
\hline Injection injury & Bleeding disorders \\
\hline Penetrating trauma & Arterial injury \\
\hline Constrictive dressings & Reperfusion \\
\hline Casts & Extravasation of drugs \\
\hline
\end{tabular}

The incidence is thought to be 3.1 per 100000 population, with males ten times more commonly affected than females $[16,17]$.

\section{OUTCOME}

Prognosis is dependent on a number of factors:

- $\quad$ Injury severity.

- Duration of ischaemia. 


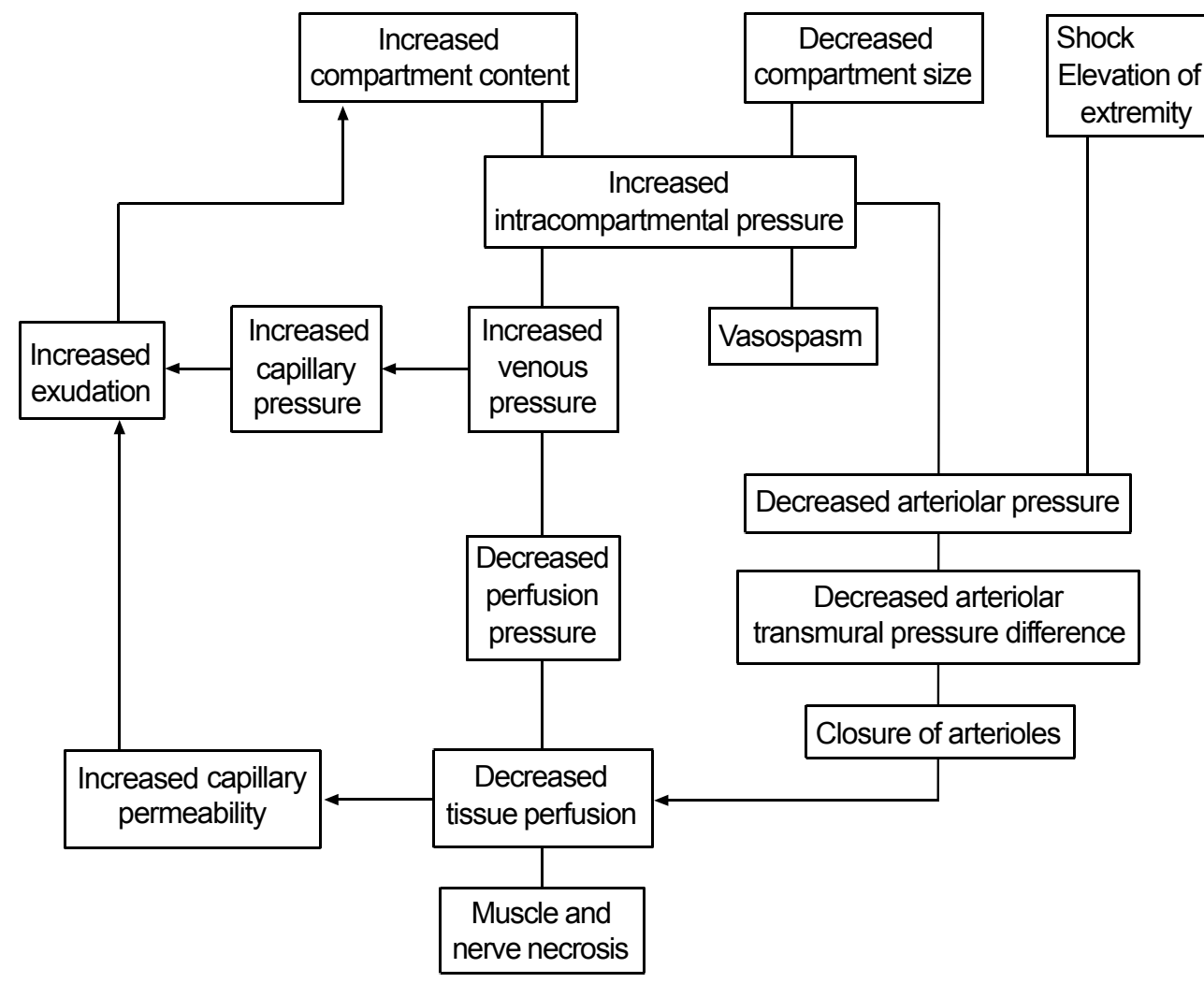

Fig. (1). Pathophysiology of compartment syndrome. (C) 2011 American Academy of Orthopaedic Surgeons. Reprinted from the Journal of the American Academy of Orthopaedic Surgeons, Volume 19 [1], pp. 49-58 with permission.

- $\quad$ Pre-injury status and comorbidities.

- $\quad$ And most importantly time to fasciotomy.

Rorabeck concluded 'almost complete recovery of limb function if fasciotomy was performed within six hours' [18]. When fasciotomy was performed within twelve hours normal limb function was regained in only $68 \%$ of patients; after twelve hours only $8 \%$ regained normal function [19].

With late diagnosis, irreversible tissue ischaemia develops causing potentially disastrous neurological deficits, muscle necrosis, ischaemic contracture, infection, chronic pain, delayed fracture union [20], rhabdomyolysis [21], amputation, and even death.

\section{DIAGNOSIS}

ACS is a clinical diagnosis; the most important determinant of outcome is early recognition and expeditious surgical intervention $[22,23]$.

Classically the five Ps (pain, pallor, pulselessness, paralysis and paraesthesia) are taught as the symptoms heralding a compartment syndrome. Pain is usually 'out of proportion' to the injury requiring increasing doses of strong opiates. The pain is often described as burning, deep in nature and is reproduced with passive stretching of the muscles in that compartment. In severe trauma or when the patient is unconscious pain may, however, be difficult to assess. Pain is also subjective and has a poor sensitivity [24].

Pulselessness and paralysis are rare, only occurring after an arterial injury or after a substantial amount of time has elapsed. Clues may also be evident from the history: highenergy injuries, anticoagulation therapy or haemophilia significantly increase the likelihood of developing ACS.

Physical signs are often few but there may be a firm, wooden feeling on deep palpation. Reduced two-point discrimination or vibration sense may be found in the early stages; if a major sensory deficit is evident the syndrome is already far advanced.

'Pain out of proportion to the injury' and 'pain with passive stretching of the muscles in the compartment' are the earliest, most reliable indicators of ACS [25].

If the diagnosis is not in doubt, emergent surgical fasciotomy is needed. Where doubt remains, the intracompartmental pressures can be measured. A transducer connected to a catheter is introduced under aseptic conditions into the compartment in question within $5 \mathrm{~cm}$ of the zone of injury. Proprietary devices are available (e.g. Stryker monitor [26]) or a transducer can be fashioned from standard hospital equipment [27] (Fig. 2). The anterior compartment is the most affected and accessible in the leg and often compartment pressures are measured here first. All compartments in the affected limb should be measured if there is enough clinical concern [28]; marginal readings should be repeated with further compartment pressure readings and repeat physical exam.

Many authors advocate the use of continuous intracompartmental pressure monitoring in all at risk patients [29] and those where extra clinical vigilance is advised [30]. It has also been suggested that pressure monitoring may 'detect 
ACS prior to the onset of clinical signs, in addition to reducing the time to fasciotomy and the development of subsequent sequelae' [31], 'whilst not increasing the rate of fasciotomy or associated complications' [32].

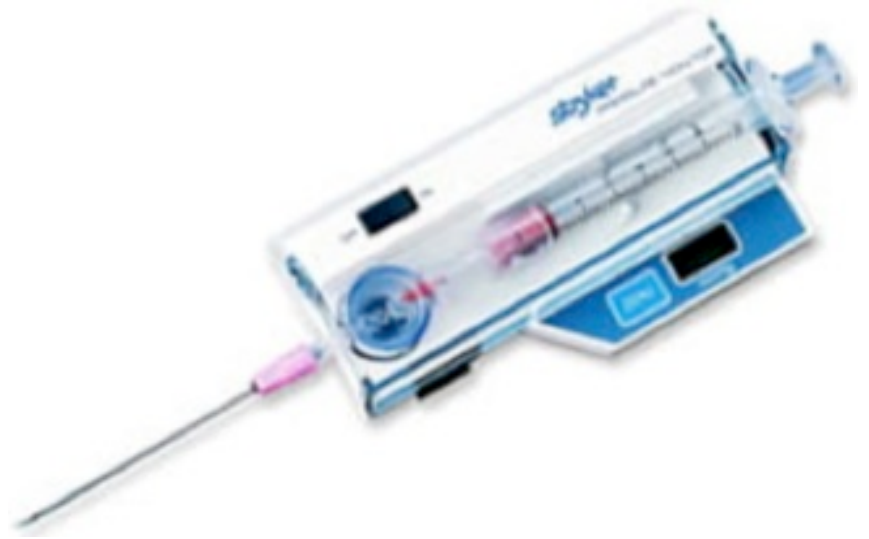

Fig. (2a). Stryker compartment pressure measurement device.

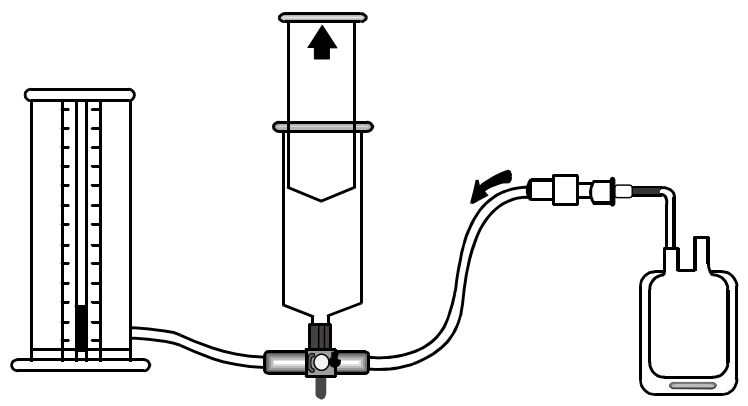

normal saline

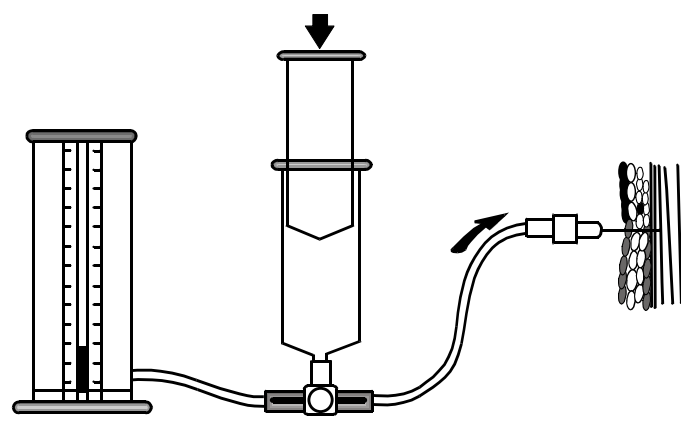

Fig. (2b). Pressure transducer using a normal saline injection and standard manometer.

The normal intra-compartmental pressure of healthy muscle is roughly $10 \mathrm{mmHg}$ [33]. Initial studies showed absolute intra-compartmental pressure values of $30 \mathrm{mmHg}$, $45 \mathrm{mmHg}$ and $50 \mathrm{mmHg}$ as the critical threshold above which circulation is compromised. The lower level of 30 $\mathrm{mmHg}$ has been more commonly quoted as animal studies have shown that muscle blood flow cannot be maintained and the fascia is maximally stretched [34].

Whitesides et al. [35] subsequently introduced the concept that the threshold at which irreversible damage was done is variable and dependent on the perfusion pressure.
This takes into account the variability of the patient's blood pressure maintaining (or not) adequate tissue perfusion. The pressure difference or 'delta pressure' is the diastolic blood pressure minus intra-compartmental pressure. McQueen and Court-Brown [36] prospectively studied 116 patients with diaphyseal tibial fractures and concluded a threshold delta pressure for decompression of $30 \mathrm{mmHg}$ led to 'no missed cases, unnecessary fasciotomies or significant complications' of ACS. White et al. studied 101 patients and validated a delta pressure of $30 \mathrm{mmHg}$ or less [37].

\section{TREATMENT}

Immediate management involves the identification and removal of external compressive forces, and releasing casts or dressings down to the skin. The limb should not be elevated and instead kept at the level of the heart so as not to decrease arterial flow any further [38].

Early assessment of hypovolaemia, metabolic acidosis and myoglobinaemia is mandatory to avoid potential renal failure. Intravenous fluids and supplemental oxygen may be needed, as well as regular blood biochemistry and urinalysis. It is important to maintain normotension as hypotension may decrease perfusion further and compound any existing tissue injury [39].

If the clinical features of ACS do not improve following simple measures, definitive surgical fasciotomy is required on an emergency basis. In conjunction with fasciotomy, orthopaedic, vascular and plastic surgery input may often be necessary to deal with concomitant injuries. Primary amputation can be considered if the diagnosis is delayed, there is no muscle function and there has been significant trauma to that limb.

The principles of fasciotomy include:

- $\quad$ Adequate and extensile incision

- Complete release of all involved compartment

- $\quad$ Preservation of vital structure

- Thorough debridement

- $\quad$ Skin coverage at a later date (7-10 days)

Post-operative pain is a major feature of ACS and adequate analgesia should be prescribed on a regular basis. The patient should be monitored closely for potential complications, in particular rhabdomyolysis and acute renal failure. An adequate urine output of $>0.5 \mathrm{~mL} / \mathrm{kg}$ should be maintained with additional intravenous fluid administration. Mannitol has been used in the past as an adjunct in an attempt to lower intra-compartmental pressure, but may be more helpful in ischaemic-reperfusion injuries [40].

\section{LEG}

The leg consists of four anatomical compartments (Fig. 3):

1. Anterior compartment containing tibialis anterior, extensor digitorum longus, extensor hallucis longus and peroneus tertius. 


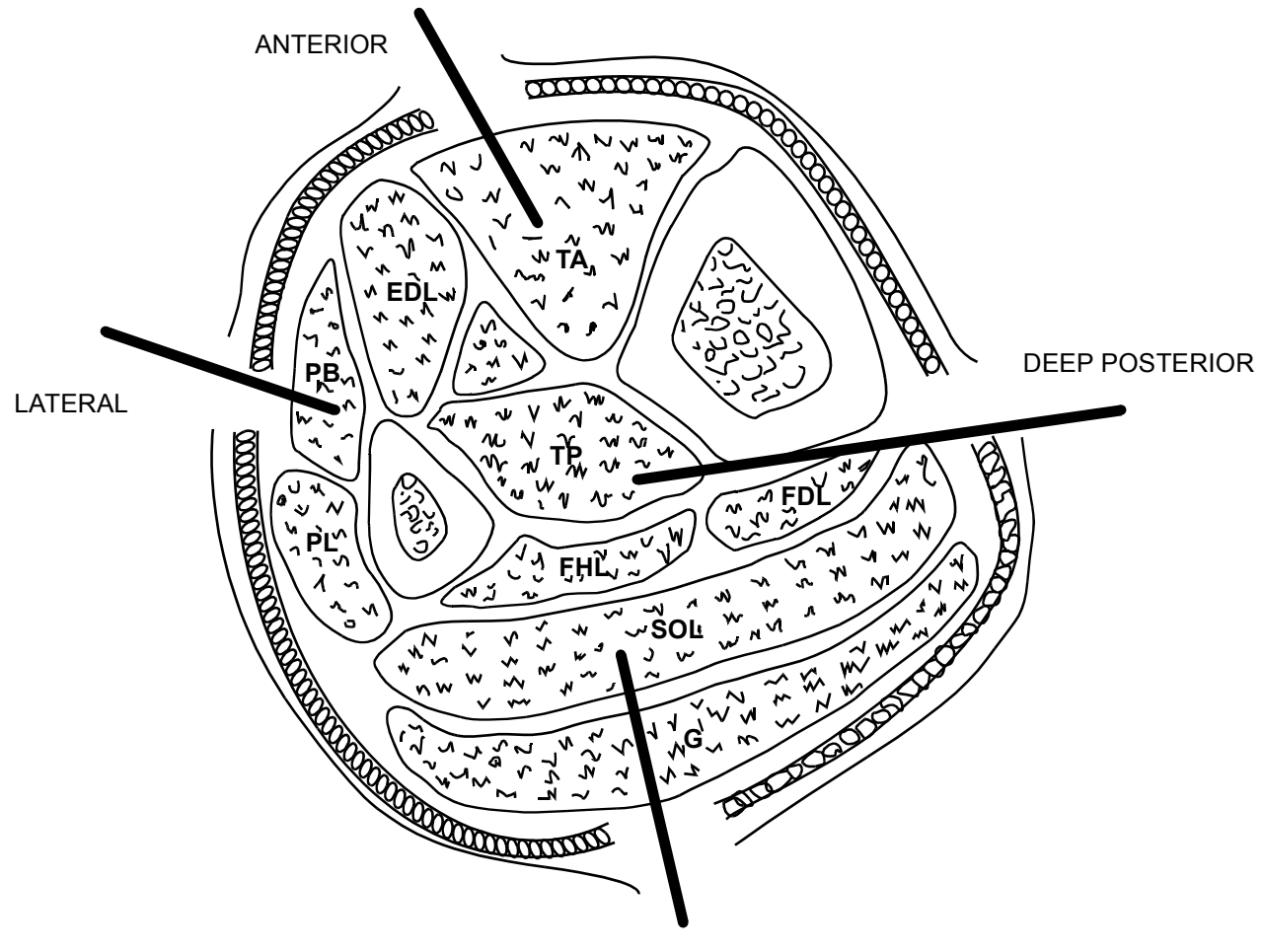

SUPERFICIAL POSTERIOR

Fig. (3). The compartments of the leg.

2. Lateral compartment containing peroneus longus and brevis.

3. Posterior superficial containing the gastrosoleus complex.

4. Posterior deep compartment containing tibialis posterior, flexor hallucis longus and flexor digitorum longus.
The two-incision technique is recommended by the British Orthopaedic Association and British Association of Plastic Reconstructive and Aesthetic Surgeons [41] (Fig. 4). The anterolateral incision is placed halfway between the tibial crest and the shaft of the fibula over the anterior intermuscular septum. A long $(20-25 \mathrm{~cm})$ incision is made along the length of the leg. A transverse incision in the fascia

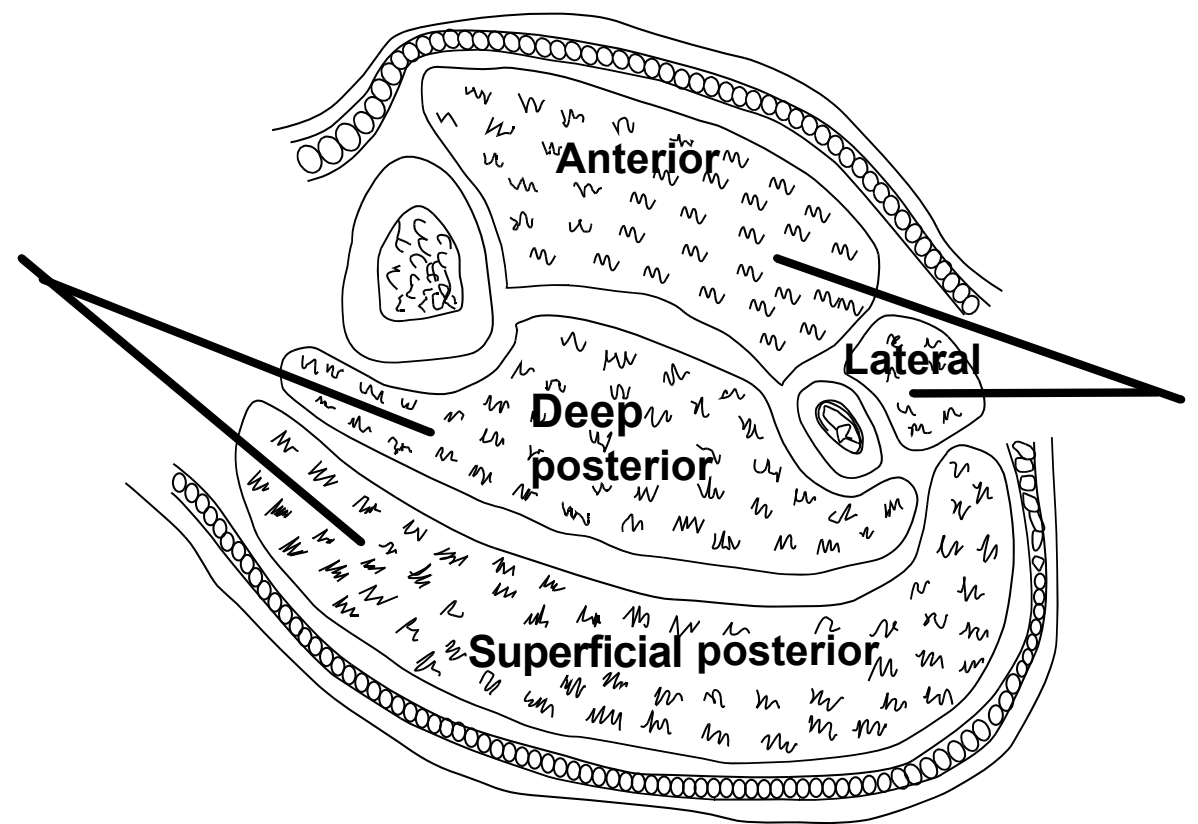

Fig. (4). Fasciotomy of the leg. 
then allows identification of the anterior intermuscular septum. The anterior and lateral compartments can then be released taking care to avoid the superficial peroneal nerve just posterior to the intermuscular septum. The medial incision is made about $2 \mathrm{~cm}$ behind the medial tibial border, ensuring a sufficient skin bridge $(>5 \mathrm{~cm})$ between the two incisions. Blunt dissection allows visualisation of the fascia. A transverse incision can then be made between the deep and superficial compartments. Both compartments can then be fully decompressed. The soleus is firmly adherent to the posterior tibia and may need to be released to adequately decompress the deep compartment.

\section{THIGH}

The thigh has three compartments (Fig. 5):

1. Anterior compartment consisting of the quadriceps muscles

2. Posterior compartment consisting of the hamstring muscles

3. Medial compartment consisting of the adductor muscles

A single lateral incision is usually adequate to decompress the thigh as the medial compartment is only rarely involved. A long lateral incision is used spanning the length of the thigh. The fascia lata is incised in line of its fibres and the anterior compartment decompressed. The vastus lateralis can be retracted anteriorly to allow access to the posterior compartment for further decompression. As mentioned it is rare to need to decompress the medial compartment but if necessary a separate medial incision can be used (Fig. 5).

\section{FOREARM}

The forearm can be anatomically divided into three compartments (Fig. 6):
1. Mobile wad comprising brachioradialis, extensor carpi radialis longus and brevis muscles

2. Volar compartment comprising superficial and deep flexors

3. Dorsal compartment containing the extensor muscles

Pronator quadratus may be described as a separate compartment.

A volar Henry approach provides exposure to adequately decompress the flexor compartments and the mobile wad. The incision is started $1 \mathrm{~cm}$ proximal and $2 \mathrm{~cm}$ lateral to the medial epicondyle extending to the mobile wad. It is carried distally to the midline down to the proximal wrist crease. Median nerve decompression is always performed at the same time. To decompress the dorsal compartment a single straight incision from the distal aspect of the lateral epicondyle aiming to the centre of the wrist (Thompson's approach) can be utilised.

\section{HAND}

The hand has ten separate osseo-fascial compartments:

- $\quad$ Four dorsal interossei

- Three palmar interossei

- The thenar and hypothenar compartments

- $\quad$ Adductor pollicis

Fasciotomy is achieved using a four-incision technique (Fig. 7). One is on the radial side of the thumb releasing the thenar compartment. Two dorsal incisions are made over the index metacarpal and over the ring metacarpal. These incisions are used to release the dorsal and volar interossei. Adductor pollicis can also be reached using the index metacarpal incision. The hypothenar muscles are released using an incision at the ulna aspect of the little finger.

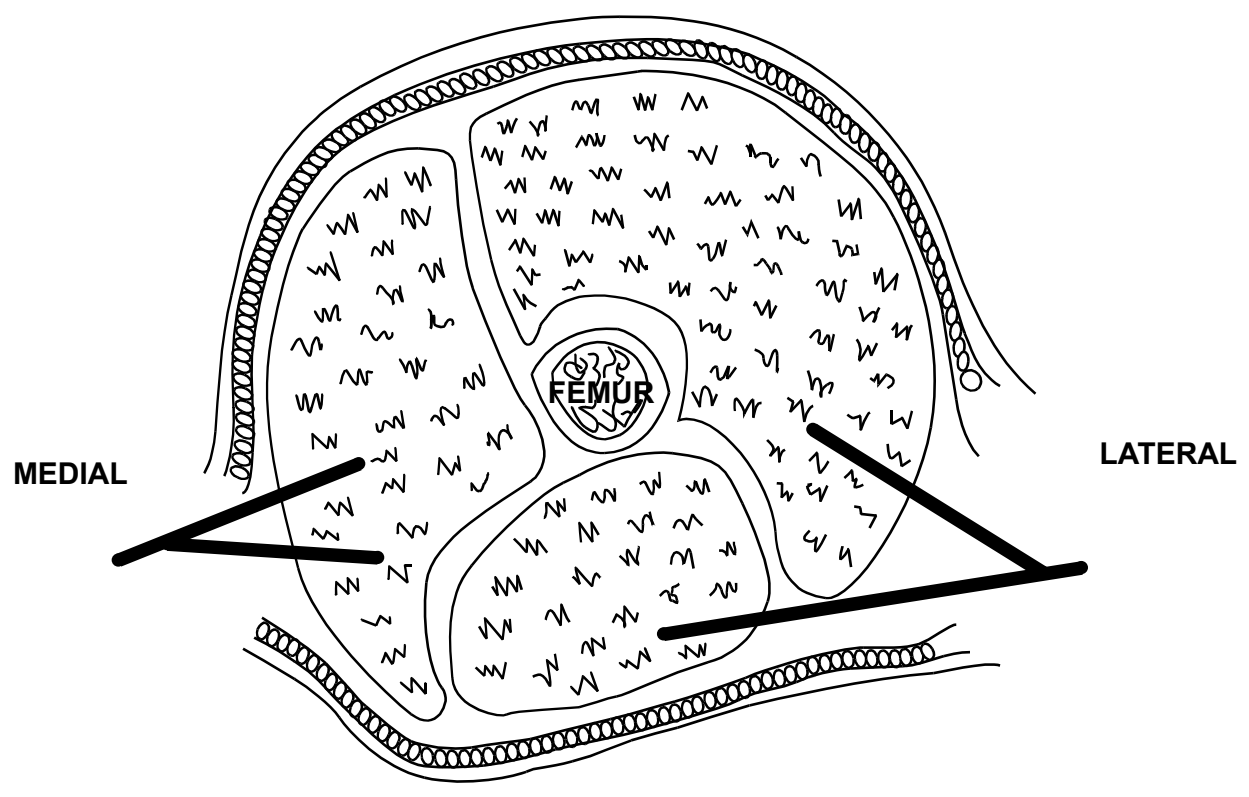

Fig. (5). Approaches for thigh fasciotomy. 


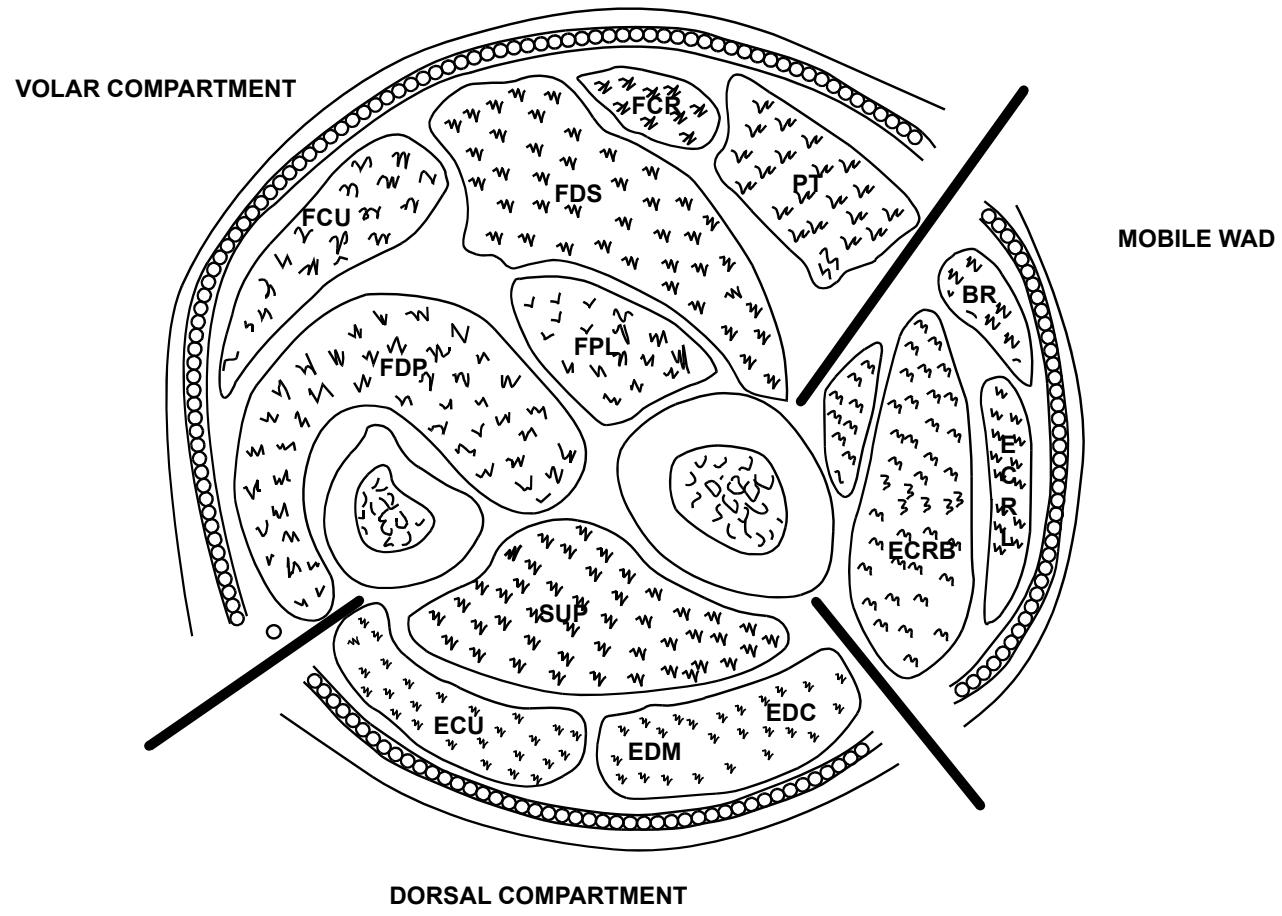

Fig. (6). Compartments of the forearm.

\section{FOOT}

Foot compartment syndrome is controversial both in terms of anatomy and in terms of treatment. Some authors advocate four compartments (medial, lateral, central and interosseous); others have expanded on this creating nine:
- $\quad$ Medial

$$
\begin{aligned}
& \circ \quad \text { abductor hallucis } \\
& \circ \quad \text { flexor hallucis brevis }
\end{aligned}
$$

- Lateral

- abductor digiti minimi

- flexor digiti minimi brevis
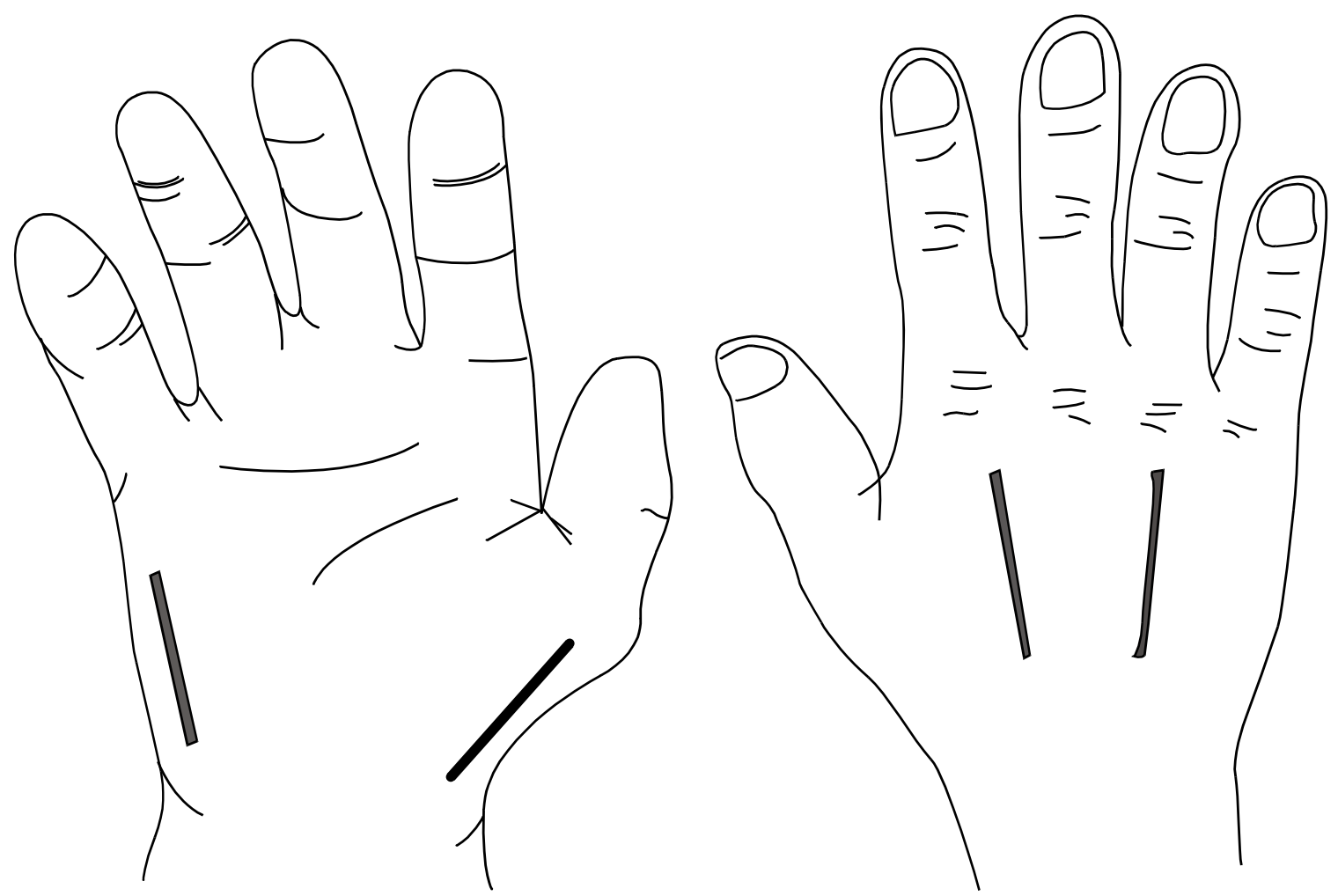

Fig. (7). The four incisions to decompress the hand. 


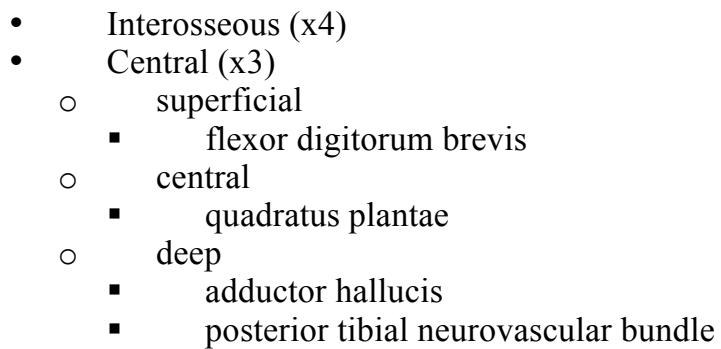

Traditional treatment involves urgent fasciotomy using the following incisions (Fig. 8):

- 2 dorsal incisions overlying the $2^{\text {nd }}$ and $4^{\text {th }}$ metatarsals. Care is needed to maintain an adequate skin bridge. The superficial fascia is divided and the interossei are elevated off the metatarsals. Blunt dissection can then be continued through the central, medial and lateral compartments.

- A medial incision along the inferior border of the $1^{\text {st }}$ metatarsal or a calcaneal incision beginning posteromedially towards the $1^{\text {st }}$ metatarsal will allow more extensive decompression of the central compartment, which may be helpful with hindfoot involvement.

More recently, however, some authors now suggest a 'supervised neglect' approach accepting the inevitable deformity and clawing and suggesting reconstruction at a later date to avoid the high risk of potential surgical complications.

\section{DELAYED FASCIOTOMY}

Fasciotomy after 8 hours in cases of ACS is controversial. The myoneural damage is irreversible at this stage and the increased risks may outweigh any potential benefit. Finkeltstein et al. described five patients with an average of 56 hours delay from the diagnosis in whom a fasciotomy was performed. One died from multi-organ failure, the remaining four required a later amputation [42]. Williams et al. found a rate of infection of $28 \%$ when fasciotomy was delayed more than twelve hours.
Where the diagnosis has been missed or delayed supportive renal treatment should be considered and surgery delayed until the morbidity has been declared and reconstruction can be planned. The evidence for this has generally come from traumatic cases. In certain cohorts (particularly haemophiliacs) this may not necessarily be the case and anecdotal evidence suggests better outcomes with delayed fasciotomy as clotting deficiencies are addressed prior to surgery.

\section{WOUND MANAGEMENT AND WOUND COMPLICATIONS}

Management of fasciotomy wounds remains controversial. Most advocate leaving the wounds open with delayed primary closure or skin grafting within 7-10 days when the compartment syndrome has completely resolved. A second look and debridement is usually necessary at 48-72 hours. Interim coverage can be achieved with simple absorbent dressings, semi-permeable membranes, vessel loops in a 'bootlace' pattern or with negative pressure dressings, which can be helpful in allowing later closure [44].

Fasciotomies are not benign procedures and there are multiple associated complications [45]:

- Altered sensation within the margins of the wound (77\%)

- $\quad$ Dry, scaly skin (40\%)

- Pruritus (33\%)

- $\quad$ Discolored wounds (30\%)

- Swollen limbs (25\%)

- Tethered scars $(26 \%)$

- Recurrent ulceration (13\%)

- Muscle herniation (13\%)

- $\quad$ Pain related to the wound (10\%)

- $\quad$ Tethered tendons (7\%)

- Chronic venous insufficiency due to impaired calf muscle pumps [46].

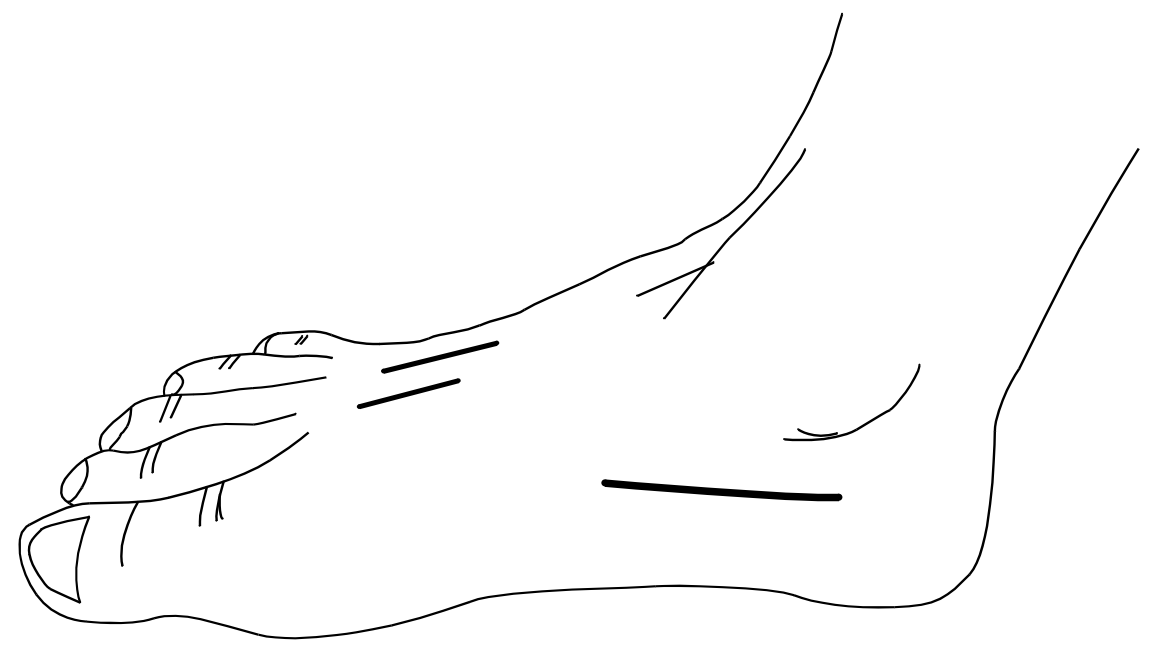

Fig. (8). Incisions for foot fasciotomy. 


\section{COMPARTMENT SYNDROME IN HAEMOPHILIA}

The lack of a clear aetiology or conspicuous traumatic injury both contribute to a potential diagnostic difficulty in haemophiliacs. In many cases the diagnosis of a bleeding disorder may not be known. The role of fasciotomy in haemophilia has been downplayed and care focuses on haemostatic manoeuvres in the first instance [47]. The absent clotting factor should be substituted and specialist haematological input sought. If these manoeuvres fail, fasciotomy is often performed to prevent muscle necrosis and future joint contracture. Caution should, however, be advised as surgical decompression can be catastrophic if the bleeding cannot be controlled and there is a higher than average amputation rate in haemophiliacs $[48,49]$.

\section{MEDICO-LEGAL PITFALLS}

ACS is a common cause of litigation. In nearly all cases, compartment pressures are never measured. Other potential pitfalls include malpositioning of the compartment pressure monitor, equipment errors and failure to correlate pressure reading with the clinical findings.

\section{CONCLUSION}

ACS is a surgical emergency and a high level of suspicion is needed in all potential cases. Compartment pressure monitoring may aid in the diagnosis, with a delta pressure of $30 \mathrm{mmHg}$ or below suggestive of ACS. The definitive treatment is prompt surgical decompression of all the involved compartments. A delay of more than six hours is associated with irreversible myoneural damage and timing is crucial. Delayed fasciotomy after 8-10 hours is associated with significantly increased risks which may outweigh any potential benefit.

\section{CONFLICT OF INTEREST}

The authors confirm that this article content has no conflict of interest.

\section{ACKNOWLEDGEMENTS}

Declared none.

\section{REFERENCES}

[1] Volkmann R. Die ischämischen Muskellähmungen und Kontracturen. Centralblatt für Chirurgie. Leipzig 1881: 8: 801-83.

[2] Jepson PN. Ischaemic contracture: experimental study. Ann Surg 1926; 84: 785-95.

[3] Ashton H. Critical closing pressure in human peripheral vascular beds. Clin Sci 1962; 22: 79-87.

[4] Ashton H. The effect of increased tissue pressure on blood flow. Clin Orthop Relat Res 1975; (113): 15-26.

[5] Matsen FA $3^{\text {rd }}$, Krugmire RB Jr. Compartmental syndromes. Surg Gynecol Obstet 1978; 147: 943-9.

[6] Hartsock LA, O'Farrell D, Seaber AV, Urbaniak JR. Effect of increased compartment pressure on the microcirculation of skeletal muscle. Microsurgery 1998; 18: 67-71.

[7] DeLee JC, Stiehl JB. Open tibia fracture with compartment syndrome. Clin Orthop Relat Res 1981; (160): 175-184.

[8] Blick SS, Brumback RJ, Poka A, Burgess AR, Ebraheim NA. Compartment syndrome in open tibial fractures. J Bone Joint Surg Am 1996; 68-A: 1348-53.
[9] Greene TL, Louis DS. Compartment syndrome of the arm - a complication of the pneumatic tourniquet: a case report. J Bone Joint Surg Am 1983; 65-A: 270-3.

[10] Schwartz JT Jr, Brumback RJ, Lakatos R, et al. Acute compartment syndrome of the thigh: a spectrum of injury. J Bone Joint Surg Am 1989; 71-A: 392-400.

[11] Kym MR, Worsing RA Jr. Compartment syndrome of the foot after an inversion injury to the ankle: a case report. J Bone Joint Surg Am 1990; 72-A: 138-9.

[12] Brumback RJ. Traumatic rupture of the superior gluteal artery, without fracture of the pelvis, causing compartment syndrome of the buttock: a case report. J Bone Joint Surg Am 1990; 72-A: 134-7.

[13] Schnall SB, Vu-Rose T, Holtom PD, Doyle B, Stevanovic M. Tissue pressures in pyogenic flexor tenosynovitis of the finger: compartment syndrome and its management. J Bone Joint Surg Br 1996; 78-B: 7935.

[14] Saggi BH, Sugerman HJ, Ivatury RR, Bloomfield GL. Abdominal compartment syndrome. J Trauma 1998; 45: 597-609.

[15] Khan WS, Malik AA. Acute compartment syndrome on the intensive care unit: a life and limb threatening emergency. In: LeClaire SE, Ed. Intensive Care Units: Stress, Procedures and Mortality Rates, 2010, Nova Science Publishers, New York. ISBN: 978-1-61728-967-5; pp. 159-168.

[16] McQueen MM, Gaston P, Court-Brown CM. Acute compartment syndrome: who is at risk? J Bone Joint Surg Br 2000; 82-B: 200-3.

[17] Kalyani BS, Fisher BE, Roberts CS, Giannoudis PV. Compartment syndrome of the forearm: a systematic review. J Hand Surg Am 2011; 36: $535-43$.

[18] Rorabeck CH, Macnab I. The pathophysiology of the anterior tibial compartmental syndrome. Clin Orthop Relat Res 1975; (113): 52-7.

[19] Sheridan GW, Matsen FA $3^{\text {rd }}$. Fasciotomy in the treatment of the acute compartment syndrome. J Bone Joint Surg Am 1976; 58(1): 112-5.

[20] Court-Brown CM, McQueen MM. Compartment syndrome delays tibial union. Acta Orthop Scand 1987; 58: 249-52.

[21] Rafiq I, Anderson DJ, Chuang CL, Chen TW, Chen JY. Subfascial hematoma progressed to arm compartment syndrome due to a nontransposed brachiobasilic fistula. Am J Kidney Dis 2006; 48(6): 990-2.

[22] Mabee JR, Bostwick TL. Pathophysiology and mechanisms of compartment syndrome. Orthop Rev 1993; 22(2): 175-81.

[23] Olson SA, Glasgow RR. Acute compartment syndrome in lower extremity musculoskeletal trauma. J Am Acad Orthop Surg 2005; 13(7): 436-44.

[24] Ulmer T. The clinical diagnosis of compartment syndrome of the lower leg: are clinical findings predictive of the disorder? J Orthop Trauma 2002; 16: 572-7.

[25] Whitesides TE, Heckman MM. Acute compartment syndrome: update on diagnosis and treatment. J Am Acad Orthop Surg 1996; 4(4): 20918.

[26] Stryker Corporation. Kalamazoo, MI. United States of America.

[27] Rockwood CA Jr, Green DP, Bucholz RW, Heckman JD, Eds. Rockwood and Green's Fractures in Adults. $4^{\text {th }}$ ed. Philadelphia, PA: Lippincott-Raven 1996.

[28] Matsen FA $3^{\text {rd }}$, Clawson DK. The deep posterior compartmental syndrome of the leg. J Bone Joint Surg Am 1975; 57-A: 34-9.

[29] McQueen MM, Court-Brown CM. Early diagnosis of compartment syndrome: continuous pressure measurement or not? Injury 2010; 41: 431-2.

[30] McQueen MM, Christie J, Court-Brown CM. Acute compartment syndrome in tibial diaphyseal fractures. J Bone Joint Surg Br 1996; 78B: $95-8$

[31] Mabvuure NT, Malahias M, Hindocha S, Khan WS, Juma A. Acute compartment syndrome of the limbs: current concepts and management. Open Orthop J 2012; 6: 535-43.

[32] Al-Dadah OQ, Darrah C, Cooper A, Donell ST, Patel AD. Continuous compartment pressure monitoring $v s$ clinical monitoring in tibial diaphyseal fractures. Injury 2008; 39:1204-9.

[33] Giannoudis PV, Tzioupis C, Pape HC. Early diagnosis of tibial compartment syndrome: continuous pressure measurement or not? Injury 2009; 40: 341-2.

[34] Hargens AR, Akeson WH, Mubarak SJ, et al. Fluid balance within the canine anterolateral compartment and its relationship to compartment syndromes. J Bone Joint Surg Am 1978; 60-A: 499-505.

[35] Whitesides TE, Haney TC, Morimoto K, Harada H. Tissue pressure measurements as a determinant for the need for fasciotomy. Clin Orthop 1975; 113: 43-51. 
[36] McQueen M, Court-Brown CM. Compartment Monitoring in Tibial fractures. J Bone Joint Surg Br 1996; 78-B: 99-104.

[37] White TO, Howell GE, Will EM, Court-Brown CM, McQueen MM. Elevated intramuscular compartment pressures do not influence outcome after tibial fracture. J Trauma 2003; 55: 1133-8.

[38] Matsen FA $3^{\text {rd }}$, Wyss CR, Krugmire RB Jr, Simmons CW, King RV. The effects of limb elevation and dependency on local arteriovenous gradients in normal human limbs with particular reference to limbs with increased tissue pressure. Clin Orthop Relat Res 1980; (150): 187-95.

[39] Daniels M, Reichman J, Brezis M. Mannitol treatment for acute compartment syndrome. Nephron 1998; 79(4): 492-3.

[40] Malik AA, Khan WS, Chaudhry A, Ihsan M, Cullen NP. Acute compartment syndrome - a life and limb threatening surgical emergency. J Perioper Pract 2009; 19(5): 137-42.

[41] British Orthopaedic Assocation and British Association of Plastic Reconstructive and Aesthetic Surgeons. Standards for Trauma 4; 2009.

[42] Finkelstein JA, Hunter GA, Hu RW. Lower limb compartment syndrome: course after delayed fasciotomy. J Trauma 1996; 40: 342-4.

[43] Williams AB, Luchette FA, Papaconstantinou HT, Lim E, Hurst JM, Johanniqman JA, Davis K Jr. The effect of early versus late fasciotomy in the management of extremity trauma. Surgery 1997; 122:861-6.
[44] Bhattacharyya T, Vrahas MS. The medical-legal aspects of compartment syndrome. J Bone Joint Surg Am 2004; 86-A: 864-8.

[45] Fitzgerald AM1, Gaston P, Wilson Y, Quaba A, McQueen MM. Longterm sequelae of fasciotomy wounds. Br J Plast Surg 2000; 53(8): 6903.

[46] Bermudez K, Knudson M, Morabito D. Fasciotomy, chronic venous insufficiency and the calf muscle pump. Arch Surg 1998; 133: 1356-61.

[47] World Federation of Haemophilia Guidelines for the Management of Haemophilia. Updates 2013. Available from: http://www.wfh.org/en/resources/wfh-treatment-guidelines

[48] Rajic N, Savic A, Popovic S, Urosevic I, Savic I. Successful control of bleeding during supracondylar amputation caused by severe compartment syndrome in patient with haemophilia A and high titre of inhibitor. Haemophilia 2009; 15(2): 601-2.

[49] Negrier C, Goudemand J, Sultan Y, Bertrand M, Rothschild C, Lauroua P. Multicenter retrospective study on the utilization of FEIBA in France in patients with factor VIII and factor IX inhibitors. French FEIBA Study Group. Factor Eight Bypassing Activity. Thromb Haemost 1997; 77(6): 1113-9.

(C) Donaldson et al.; Licensee Bentham Open.

This is an open access article licensed under the terms of the Creative Commons Attribution Non-Commercial License (http://creativecommons.org/licenses/by-nc/3.0/) which permits unrestricted, non-commercial use, distribution and reproduction in any medium, provided the work is properly cited. 